$$
\text { DOE/PC/79892-T/8 }
$$

Technical Progress Report

for the Fourteenth Quarter

DOE/PC/79892--T1 8

(July 1, 1991 - September 30, 1991)

DE92 013184

\title{
DEVELOPMENT OF THE CHEMICAL AND ELECTROCHEMICAL COAL CLEANING PROCESS
}

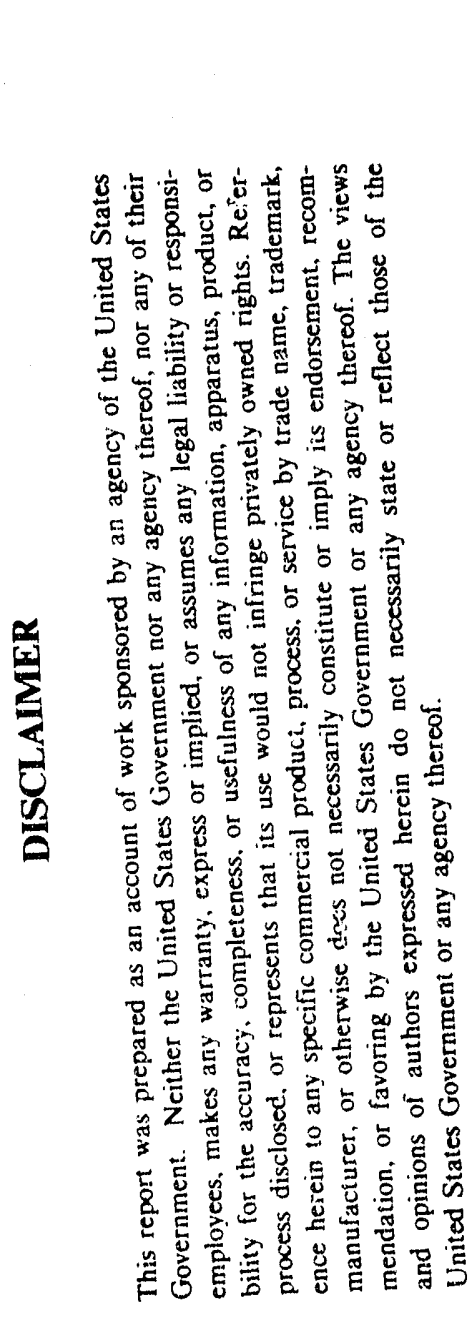

\author{
by \\ Cesar I. Basilio and Roe-Hoan Yoon \\ Department of Mining and Minerals Engineering \\ Virginia Polytechnic Institute and State University \\ Blacksburg, Virginia 24061
}

Contract Number:

DE-AC22-87PC79892

\section{Project Manager}

Richard Read

U.S. Department of Energy

Pittsburgh Energy Technology Center

P.O. Box 10940

Pittsburgh, Pennsylvania 15236

\section{WisteR}

U.S. DOE patent clearance not required prior to publication of this document. 


\begin{abstract}
Liberation studies on the Elkhorn No. 3 coal were completed in this quarter. The results obtained from the $65 \times 150$ mesh samples showed that the amount of mineral matter and pyrite liberated by the CECC process increases ivith time. The free mineral matter undergoes some reduction in size during the CECC treatment and the majority of the liberated mineral particles in this sample are finer than 150 mesh. This is opposite that found for the Pittsburgh No. 8 coal, which may explain the better response of the Elkhorn No. 3 coal to CECC treatment.

The continuous bench-scale unit was modified during the quarter to satisfy the health and safety requirements of the university. The unit was modified to ensure that any spill or leakage can be contained. Duc to these modifications, continuous testing work (subtask 6.2) was delayed.
\end{abstract}

\title{
PROJECT OBJECTIVES
}

The objectives of this work are to: (a) determine the mechanisms by which the CECC process ramoves ash and pyritic sulfur from coal, (b) learn more about the operating parameters of the process, (c) collect engineering information for the scaie-up of the process, and (d) test the CECC process as a bench-scale continuous operation. 


\section{PROJECT TASKS}

Task 4 - Batch Testing

An investigation into the liberation of mineral matter from Elkhorn No. 3 coal by the CECC process was conducted during the quarter. This study was conducted on a $65 \times 150$ mesh sample using the Scanning Electron Microscope-Image. Processing System (SEM-IPS). The feed and processed coal were analyzed for size distribution pertaining to the free coal, free mineral matter, free pyrite and various locked classes of composite particles.

\section{Subtask 4.3 - Mechanistic Studies}

\section{Liberation Analysis}

The Elkhorn No. 3 coal samples were treated under optimum CECC processing conditions for different periods of time. Slurry samples were collected from the reactor after treatment and the solids were recovered from the slurry, dried and used for the liberation analysis. The ash analysis results obtained are given in Table I. As expected, the amount of mineral matter removed by the CECC process increased with treatment time. The \% ash rejection increased from $34 \%$ to about $51.5 \%$ when length of treatment was increased from 1 to 8 hours. However, there was no significant improvement in the rejection of mineral matter between treatment times of 5 and 8 hours, indicating that treatment times longer than 5 hours may not be necessary in the CECC processing of the Elkhorn No. 3 coal.

The amount of mineral matter removal that may be attributed to liberation decreases with treatment time. This decrease is probably due to the dissolution of the liberated mineral matter, 
TABLE I

Ash Analysis Results of the CECC Treatment of Elkhorn No. 3 Coal

\begin{tabular}{|c|c|c|c|c|c|c|c|}
\hline \multirow{2}{*}{$\begin{array}{c}\text { Treatment } \\
\text { Time } \\
(\mathrm{hrs})\end{array}$} & \multicolumn{3}{|c|}{ Ash Content $(\% \mathrm{wt})$} & \multicolumn{3}{c|}{ Ash Rejection $(\% \mathrm{wt})$} & \multirow{2}{*}{$\begin{array}{c}\text { Yield } \\
(\% \mathrm{wt})\end{array}$} \\
\cline { 2 - 9 } & Feed & Product & Reject & Total & Liberated & Dissolved & ( \\
\hline 1 & 22.08 & 17.57 & 45.30 & 34.43 & 88.59 & 11.41 & 87.40 \\
\hline 3 & 22.08 & 15.05 & 37.86 & 46.25 & 70.63 & 29.37 & 83.85 \\
\hline 5 & 22.08 & 14.51 & 38.43 & 49.20 & 74.42 & 25.58 & 82.30 \\
\hline 8 & 22.08 & 14.03 & 38.72 & 51.53 & 70.56 & 29.44 & 81.28 \\
\hline
\end{tabular}

- and/or lost 
but can also be attributed to the reduction in size that occurs when locked particles are liberated. Similar observations were reported in the Tenth Quarter for the Pittsburgh No. 8 coal.

Table II shows the total sulfur removed in the same tests. The \% sulfur rejection (by weight) increases with treatment time. After 8 hours of CECC treatment, a sulfur rejection of about $25 \%$ is obtained. However, the sulfur content of the product is not significantly different from that of the feed.

The response of the Elkhorn No. 3 coal sample obtained in this quarter is poorer than that obtained in the Eleventh Quarter. In our previous test, the \% ash and sulfur rejections (by weight) obtained were about $84 \%$ and $18 \%$, respectively. However, it should be noted that the ash and pyritic sulfur contents of the sample used in this study are higher than those of the sample used in the Eleventh Quarter. The higher pyritic sulfur content is probably responsible for the poorer response of this coal to CECC treatment. It was found previously that a higher pyrite content has a detrimental effect on the removal of mineral matter by the CECC process. This was explained as being due to excessive amounts of $\mathrm{Fe}^{3+}$ ions coming from pyrite and other ferruginous minerals. The presence of excessive amounts of $\mathrm{Fe}^{3+}$ ions may lead to jarosite formation, which prevents the further liberation of mineral matter. The oxidation of the feed sample may also be responsible for the decrease in mineral matter removal.

Figure 1 shows the percentage of the total mineral matter that is liberated as a function of time for three different size fractions: $65 \times 100,100 \times 150$ and -150 mesh. The percentages of free mineral matter present in the feed for each size fraction are given by the values at 0 hours. The total percentage of free mineral matter $(65 \times 150$ mesh) in the feed is about $14.4 \%$. The curve for the $65 \times 100$ mesh fraction shows a sharp decrease in the amount of mineral 
TABLE II

Sulfur Analysis Results of the CECC Treatment of Elkhorn No. 3 Coal

\begin{tabular}{|c|c|c|c|c|}
\hline \multirow{2}{*}{$\begin{array}{l}\text { Treatment } \\
\text { Time } \\
\text { (hrs) }\end{array}$} & \multicolumn{3}{|c|}{ Sulfur Content $(\%$ wt) } & \multirow{2}{*}{$\begin{array}{c}\text { Sulfur } \\
\text { Rejection } \\
(\% \mathrm{wt})\end{array}$} \\
\hline & Feed & Product & Reject & \\
\hline 1 & 1.72 & 1.71 & 2.64 & 18.08 \\
\hline 3 & 1.72 & 1.71 & 2.37 & 21.60 \\
\hline 5 & 1.72 & 1.71 & 2.25 & 23.15 \\
\hline 8 & 1.72 & 1.69 & 2.13 & 25.05 \\
\hline
\end{tabular}


matter liberated after CECC treatment. After only 1 hour of treatment, the amount of coarse liberated mineral matter is almost negligible. The amount of liberated $100 \times 150$ mesh mineral matter found in the coal also decreased significantly in the first hour of treatment and decreased continuously with increasing treatment time.

However, the percentage of mineral matter thiat is liberated -150 mesh size particles shows an opposite trend with treatment time. During the first hour of treatment, there is a sharp increase in the amount of liberated mineral matter present in this size fraction. This value is observed to increase slightly after 3 hours and then decreases slightly with time. It should be noted that the amount of mineral matter rejection attributable to liberation also decreased (Table I). As discussed earlier, the decrease may be attributed to the size reduction and dissolution of the liberated mineral matter. Also, the size reduction of the liberated mineral matter may be producing particles that are smaller than the minimum size of 4 microns that the SEM-IPS can detect.

The results indicate that there is a change in the size of the liberated mineral matter. The liberated $65 \times 100$ mesh particles are reduced to finer sizes after CECC treatment. The same trend is observed for the $100 \times 150$ mesh particles. However, the amount of $100 \times 150$ mesh liberated particles reporting to next lower size fraction is less than that for the $65 \times 100$ mesh fraction, presumably because part of the $65 \times 100$ mesh fraction is reporting to $100 \times 150$ mesh fraction.

Based on a mass balance of the liberated mineral matter, the majority of the liberated mineral matter is finer than -150 mesh size. This observation is opposite to that found in the Tenth Quarter for the Pittsburgh No. 8 coal, where the majority of the liberated mineral matter 


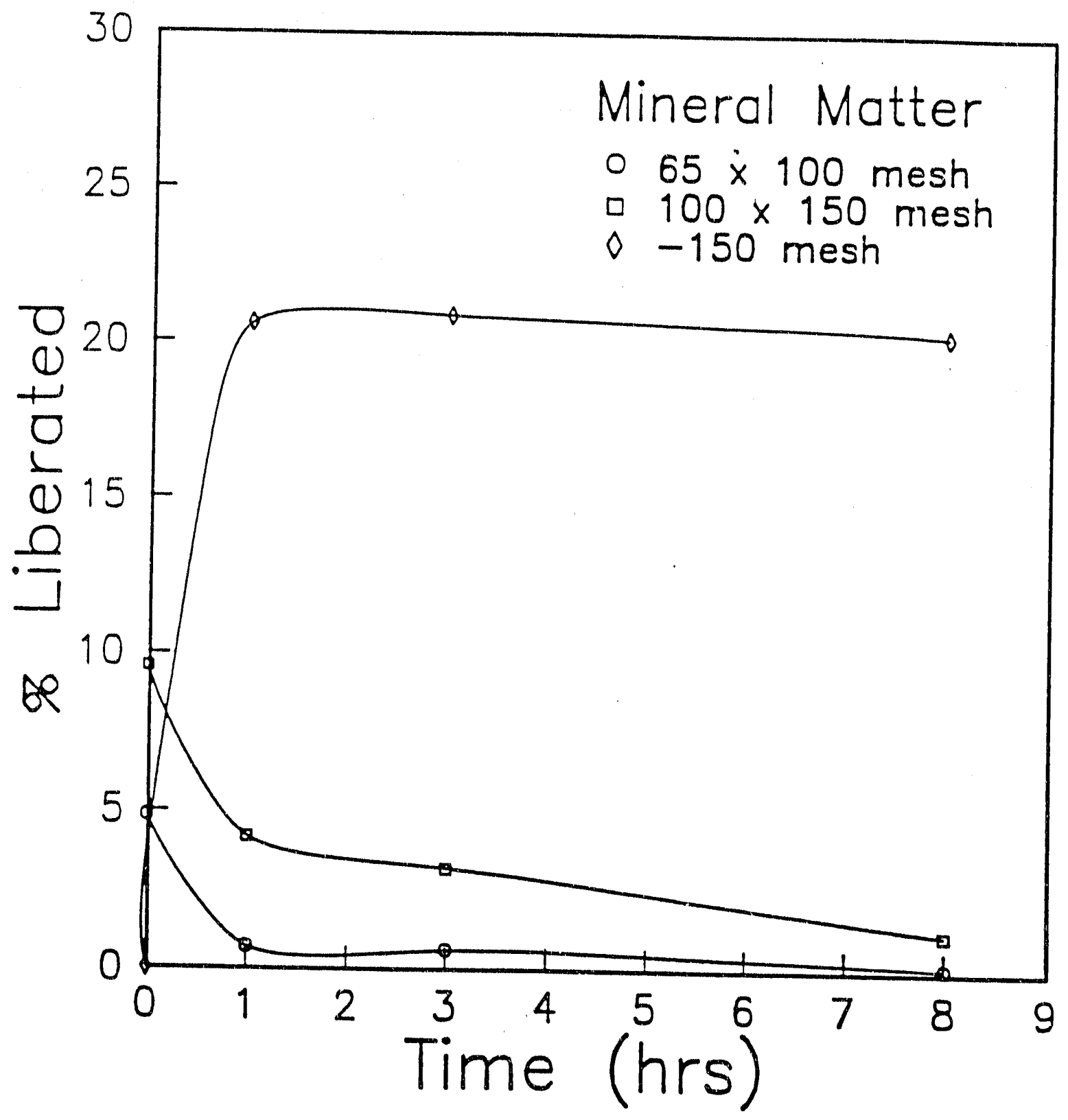

Figure 1. The amount of mineral matter that is liberated as a function of CECC treatment time for Elkhom No. 3 coal. 
is coarse. The difference observed here may be responsible for the better response of the Elkhorn No. 3 coal to the CECC process.

Although not shown here, the analysis of the locked particles indicates that the quantity of +150 mesh locked particles decreased with treatment time, while the quantity of -150 mesh locked particles showed an opposite trend. However, the mass balance for the locked particles does not indicate that the locked particles were merely breaking and going to the -150 mesh locked fraction. Thus, the mineral matter is presumably being liberated from the composite particles and reporting to the -150 mesh liberated fraction. This would account for the increase in the amount of liberated -150 mesh mineral matter.

The total amount of liberated mineral matter present after treatment is greater than that initially present in the feed. This indicates that the removal of mineral matter obtained here is not simply due to the rejection of the free mineral matter in the feed. Rather, the use of the CECC process is responsible for the removal of these particles, as well as for the liberation of some of the locked particles. The mass balance of the results, shown in Table I, supports this conclusion.

Figure 2 shows the amount of pyrite that is liberated for three different size fractions. The ratio of free pyrite to total pyrite content is higher than that for the mineral matter in this coal sample. The free pyrite accounts for about $38 \%$ of the total pyrite content in the feed, with about half of the free pyrite belonging to the $65 \times 100$ mesh size fraction. After a 1-hour treatment, the amount of pyrite that is free in the $65 \times 100$ mesh fraction is reduced significantly. This value continues to decrease, reaching zero after 8 hours. The amount of 100 x 150 mesh size free pyrite particles also decreases with treatment time. However, the decrease 


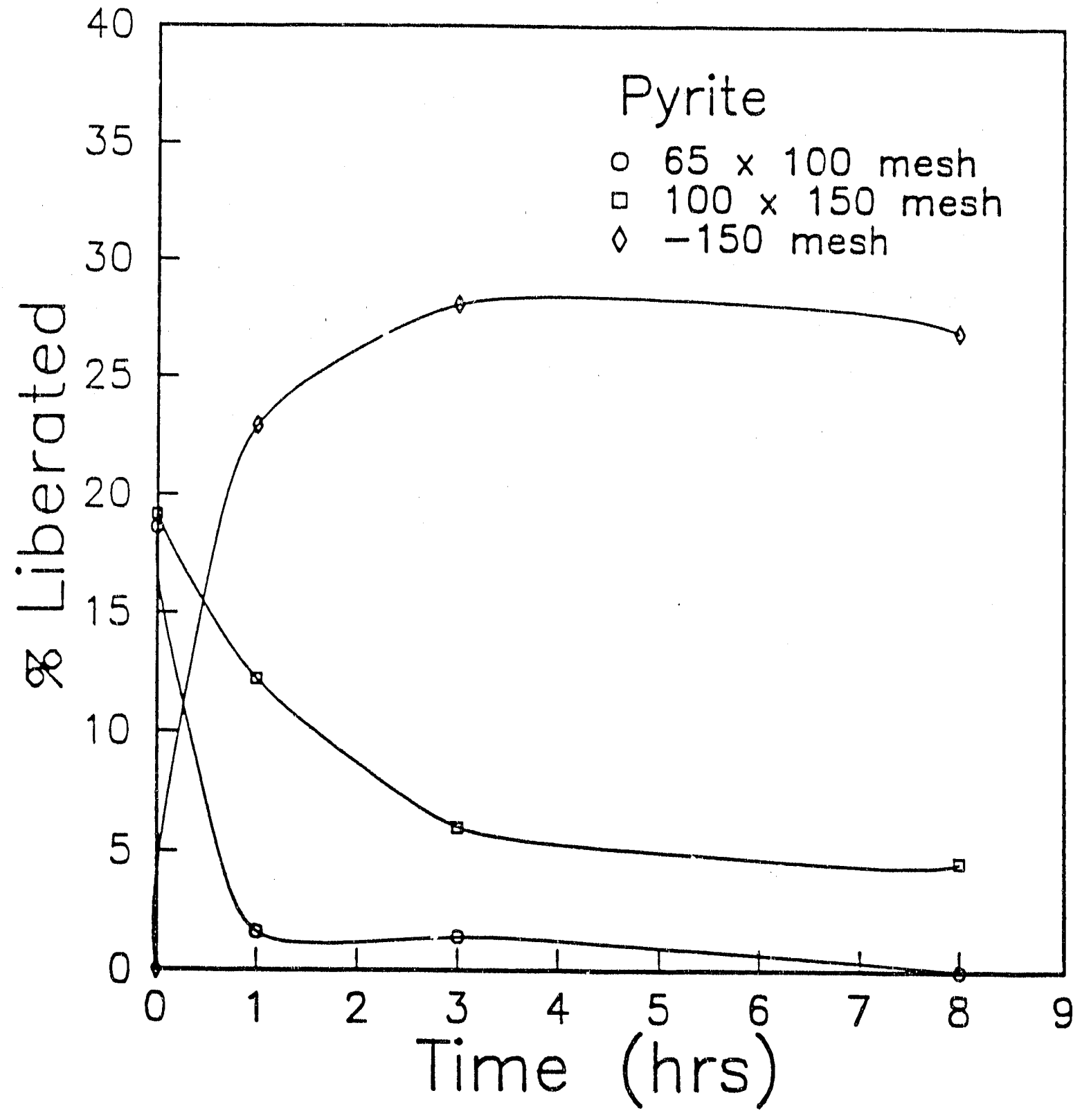

Figure 2. The amount of pyrite that is liberated as a function of CECC treatment time for Elkhorn No. 3 coal. 
is not as large as that observed for the coarser fraction, suggesting that some of the coarse liberated pyrite particles are reduced to this size. It is also possible that some of the pyrite is being dissolved in the acidic solution used in this process.

The amount of -150 mesh pyrite that is liberated increased sharply during the first lour of treatment. This value continued to increase until the 3 hour point and then decreased slightly. This behavior is similar to that found for the mineral matter and may be attributed to the same factors discussed above. However, the total amount of pyrite liberated after treatment is less than that found in the feed. This is presumably because of pyrite dissolution, which is to be expected in the acidic conditions used in this process. The fraction of -150 mesh pyrite liberated by the process is greater than the coarser fraction, which was also observed for the mineral matter. However, the overall sulfur removal for this coal is still not as significant as that for the mineral matter rejection.

Task 5 - Design and Construction of the CECC Continuous Unit

\section{Subtasks 5.3 - CECC Unit Modification}

The CECC continuous bench-scale unit, which was completed last quarter, was modified during this quarter to satisfy the strict requirements of the Health and Safety Department of the university regarding the possibility of accidental acid discharge to the sewer system. The recirculation system on the slurry mixing tank had leaked during the shakedown testing, and was replaced by a new stirred tank system. Level controllers were installed on all the tanks that did not have them previously to ensure that no tank would overflow. Heavy duty polyethylene and PVC trays were placed under all the tanks to contain any drips or leaks. Also, acid-resistant 
adsorbent dikes were placed around the base of each tank and the floor drains to prevent any spill from leaking into the sewer system. All fittings, tubing and pumps were inspected and any loose fittings or tube connections were tightened. Due to these modifications, the continuous unit was shutdown for almost the entire quarter.

\section{Task 6 - Continuous Unit Operation}

Subtasks 6.1 and 6.2 - Shakedown Testing and Continuous Test Work

The shakedown testing started last quarter using Middle Wyodak coal samples showed that the continuous unit was operating properly. However, due to the modifications made in this quarter to satisfy the health and safety requirements of the university, the continuous test work for the Middle Wyodak coal was delayed. This will be completed in the next quarter along with the continuous test work for the Elkhorn No. 3 coal. A fresh batch of run-of-mine Elkhorn No. 3 coal is being obtained for this subtask.

\section{SUMMARY AND CONCLUSIONS}

The liberation analysis of the Elkhorn No.3 coal was completed this quarter. Using image analysis, the amounts of mineral matter and pyrite liberated as a function of treatment time were determined. Tests were conducted on a $65 \times 150$ mesh sample using the optimum conditions and different treatment times. The results showed that the total amount of mineral matter that is liberated increases with time. Initially, there was a relatively large amount of free mineral matter and pyrite found present in the feed. After CECC treatment, the amount of these 
liberated particles was found to decrease. This decrease was accompanied by a significant increase in the amount of liberated particles finer than 150 mesh. The amount of -150 mesh liberated mineral matter was found to be greater than that of the +150 mesh free mineral matter initially present in the feed. This would indicate that liberation of some of the locked particles was also occurring, along with the size reduction of the free mineral matter present in the feed. Analysis of the composite particles verified this suggestion. Similar trends were also observed regarding the liberation of pyrite in this sample.

However, the amount of mineral matter rejected in these tests was lower than had been observed in our previous tests. This is probably due to the detrimental effect of the higher pyritic sulfur content of this sample, which contained higher quantities of ash and pyritic sulfur than those of the sample used in the Eleventh Quarter.

The continuous unit was modified in this quarter to satisfy the requirements of the Health and Safety Department of this university. Modifications were made to ensure that acid spillage wouiu not go to the sewer system. The slurry mixing tank was replaced and acid-resistant trays and containers were placed under each tank and reactor. Additional level controllers were added to ensure that none of the acid containers will overflow. These modifications now ensure that the CECC continuous unit is in strict compliance with the university requirements. However, they resulted in the prolonged shut down of the unit and the delay of the continuous test program (Subtask 6.2). 
) )

\section{PLANNED FUTURE WORK}

Task 6 - Continuous Unit Operation

Subtask 6.1 - Shakedown Testing

- Shakedown testing of the CECC unit using the Elkhorn No. 3 coal will be conducted in the next quarter following the completion of the continuous test work for the Middle Wyodak coal.

Subtask 6.2 - Continuous Test Work

- The continuous test work for the Middle Wyodak coal wiil be completed early in the next quarter.

- Continuous testing of the Elkhorn No. 3 coal will be conducted in the next quarter following the shakedown testing. Completion of this test will complete all the required work for this project. 

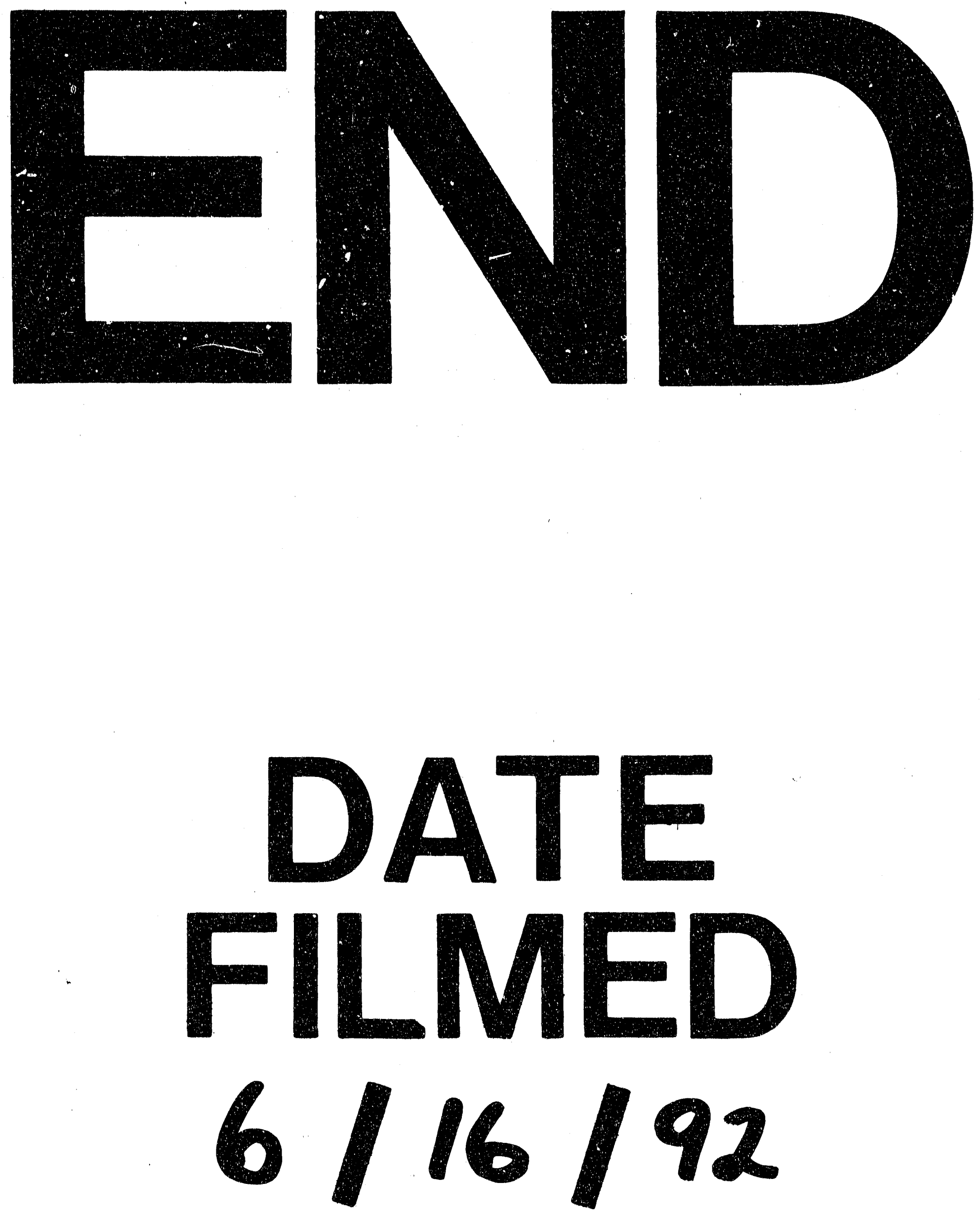


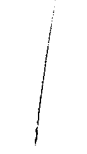

i 